\title{
Genetic Predisposition to Respiratory Diseases: Infiltrative Lung Diseases
}

\author{
Mark P. Steele ${ }^{a}$ Kevin K. Brown ${ }^{b}$ \\ ${ }^{a}$ Division of Pulmonary, Allergy, and Critical Care Medicine, Duke University Medical Center, Durham, N.C., and \\ ${ }^{b}$ Department of Medicine, Division of Pulmonary and Critical Care, National Jewish Medical and Research Center, \\ Denver, Colo., USA
}

\begin{abstract}
Key Words
Sarcoidosis - Candidate gene studies • Linkage analysis • Interstitial pneumonia, familial · Interstitial pneumonia, idiopathic
\end{abstract}

\begin{abstract}
The availability of high-throughput genotyping and large collaborative clinical networks creating well-characterized patient populations with DNA repositories has facilitated genome-wide scans and candidate gene studies to identify susceptibility alleles for the development of interstitial lung disease. The association of pulmonary fibrosis with rare inherited disorders, and the variable susceptibility of inbred mouse strains to this disease indicate that pulmonary fibrosis is determined by genetic factors. Sarcoidosis represents a complex disease with racial and ethnic differences in disease prevalence, and evidence of familial clustering. Familial aggregation of sarcoidosis from 'A Case-Control Etiologic Study of Sarcoidosis' (ACCESS) reveals a familial odds ratio (OR) of sarcoidosis of $5.8(95 \% \mathrm{Cl} 2.1-15.9)$ for sibs and $3.8(95 \% \mathrm{Cl}$ 1.2-11.3) for parents. Several HLA class II alleles have been associated with either increased or decreased risk of sarcoidosis, and results vary depending on study populations of different ethnicity. Genome-wide screening has conclusively identified linkage to chromosome $5 q 11$ and the development of sarcoidosis, and HLA genes and BTNL2 are susceptibility genes located in this region. Familial aggregation of idiopathic interstitial pneumonia (IIP) has been established by several groups, and a large US-based study suggests autoso-
\end{abstract}

mal dominant inheritance with reduced penetrance; furthermore, cigarette smoking was associated with affection status among siblings (OR $=3.6,95 \% \mathrm{Cl} 1.3-9.8, \mathrm{p}=0.01)$. Families demonstrate more than one type of IIP, suggesting various subtypes of IIP may share a common pathogenesis. Genomewide linkage scans in familial interstitial pneumonia demonstrate linkage to chromosomes 4, 5 and 11. Candidate gene studies indicate that surfactant protein $\mathrm{C}$ and telomerase are susceptibility genes for the development of pulmonary fibrosis. Future challenges include determining how multiple susceptibility alleles interact with each other and environmental factors resulting in disease risk and multiple phenotypes, and determining the mechanism of action and cellular pathways involving susceptibility alleles. Further insight into these areas may lead to new therapeutic interventions.

Copyright $\odot 2007$ S. Karger AG, Basel

Previous articles in this series: 1. Contopoulos-loannidis DG, Kouri IN, loannidis JPA: Genetic predisposition to asthma and atopy. Respiration 2007;74:8-12. 2. Sztrymf B, Yaïci A, Girerd B, Humbert $\mathrm{M}$ : Genes and pulmonary arterial hypertension. Respiration 2007;74:123-132. 3. Southern KW: Cystic fibrosis and formes frustes of CFTR-related disease. Respiration 2007;74:241-251. 4. Morillas HN, Zariwala M, Knowles MR: Genetic causes of bronchiectasis: primary ciliary dyskinesia. Respiration 2007;74:252-263. 5. Notarangelo LD, Plebani A, Mazzolari E, Soresina A, Bondioni MP: Genetic causes of bronchiectasis: primary immune deficiencies and the lung. Respiration 2007;74:264-275. 6. Cottin V, Dupuis-Girod S, Lesca G, Cordier J-F: Pulmonary vascular manifestations of hereditary hemorrhagic telangiectasia (Rendu-Osler disease). Respiration 2007;74:361-378. 7. Wood AM, Stockley RA: Alpha one antitrypsin deficiency: from gene to treatment. Respiration 2007;74:481-492.

\section{KARGER}

Fax +4161306 1234

E-Mail karger@karger.ch

www.karger.com (c) $2007 \mathrm{~S}$. Karger AG, Basel

0025-7931/07/0746-0601\$23.50/0

Accessible online at:

www.karger.com/res
Mark P. Steele, MD

Division of Pulmonary, Allergy, and Critical Care Medicine

350 Bell Building, Box 3171, Duke University Medical Center

Durham, NC 27710 (USA)

Tel. +1 919684 6140, Fax +1 919684 3067, E-Mail Steel002@mc.duke.edu 


\section{Introduction}

The interstitial lung diseases (ILDs) are a diverse group of lung diseases that can be classified according to the combination of clinical, radiologic, physiologic and pathologic criteria. The term diffuse parenchymal lung disease (DPLD) more accurately describes these entities, as beyond the alveolar interstitium, the capillaries, terminal and respiratory bronchioles, and lymphatics along the bronchovascular bundle and interlobular septae can all be pathologically involved. While the underlying pathogenic mechanisms are known or inferred in some of the DPLDs (for example hypersensitivity pneumonitis), the pathogenesis of the majority of these entities, particularly those characterized by the development of progressive lung fibrosis, is poorly understood.

Four lines of evidence suggest that the development of pulmonary fibrosis is determined by genetic factors and that the study of genetics and genomics may provide insight into the pathogenesis of these diseases. First, clustering of pulmonary fibrosis has been noted in monozygotic twins raised in different environments [1-3], in genetically related members of different families [3-6], in consecutive generations of the same family $[3,7,8]$ and in family members separated at an early age [5]. Second, pulmonary fibrosis is observed in genetic disorders with complex clinical manifestations, including HermanskyPudlak syndrome [9], neurofibromatosis [10], tuberous sclerosis [11, 12], Niemann-Pick disease [13], Gaucher disease [14], familial hypocalciuric hypercalcemia [15] and familial surfactant protein (SP)-C mutation [16]. Third, considerable variability exists in the development of pulmonary fibrosis among individuals exposed to similar concentrations of fibrogenic dusts or organic antigens. For instance, following exposure to asbestos, similarly exposed individuals experience very different outcomes $[17,18]$. Fourth, inbred strains of mice differ in their susceptibility to fibrogenic agents. In comparison to $\mathrm{BALB} / \mathrm{c}$ or 129 mice, C57BL/6 mice develop more lung fibrosis when challenged with either bleomycin $[19,20]$ or asbestos [21, 22].

This review will focus on the genetic and genomic approaches to identify disease susceptibility genes that predispose to, aid in the diagnosis, or help define the outcome of DPLD.

\section{Genetic Associations in Mouse Strains}

To date, no mouse strain has been identified that spontaneously develops a fibrosing lung disease that resembles any of the idiopathic interstitial pneumonias (IIPs). However, there are several mouse strains that have been identified as being susceptible or resistant to pulmonary fibrosis following various stresses to the lung. These differences in susceptibility can be used to identify pulmonary fibrosis susceptibility genes.

Differences in susceptibility to radiation-induced [2325], bleomycin-induced and paraquat-induced pulmonary fibrosis in different inbred mouse strains have been used to identify loci linked to pulmonary fibrosis [26-29]. Microarray analysis can be targeted to linked regions to identify differentially expressed genes that are potential candidate genes $[27,30]$. The most commonly studied model is pulmonary fibrosis following intratracheal administration of bleomycin. Using this model, the C57BL6 strain has been shown to be susceptible to the development of pulmonary fibrosis when compared to the more resistant $\mathrm{C} 2 \mathrm{Hf} / \mathrm{Kam}$ and $\mathrm{C} 3 \mathrm{H} / \mathrm{HeJ}$ strains. One limitation of the bleomycin mouse model is that the fibrosing lung injury induced by bleomycin tends to resolve spontaneously over time, with relatively little persistent fibrosis compared to the chronic and progressive disease seen in humans. In the bleomycin model, the bleomycin hydrolase gene appears to be at least one candidate gene. Results of these studies are summarized in table 1.

\section{Genetic Associations in Sarcoidosis}

Sarcoidosis represents a complex disease with racial and ethnic differences in disease prevalence $[32,33]$ and evidence of familial clustering [34-38]. The most comprehensive study of the familial aggregation of sarcoidosis comes from 'A Case-Control Etiologic Study of Sarcoidosis' (ACCESS) [32]. The study population was drawn from 10,862 first-degree and 17,047 second-degree relatives identified by 706 sarcoidosis case-control pairs. Controls were matched to cases on race, sex, age and 3digit phone numbers. The familial odds ratio (OR) of sarcoidosis was 5.8 (95\% CI 2.1-15.9) for sibs and 3.8 (95\% CI 1.2-11.3) for parents.

\section{Candidate Gene Studies}

Sarcoidosis demonstrates characteristic granulomatous inflammation with a host of associated immunologic abnormalities [39]. These immunologic abnormali- 
Table 1. Results of studies on mouse models

\begin{tabular}{|c|c|c|c|c|}
\hline Animal model & Mouse strain & Locus & Result & Reference \\
\hline Bleomycin & C57BL6 & $\begin{array}{l}\text { Chr } 17 \\
\text { Chr } 11\end{array}$ & $\begin{array}{l}\text { LOD score } 2.8 \text {, marker D17Mit198/D17Mit16 localized to } \\
2.7 \mathrm{cM} \text { region of MHC accounting for } 40 \% \text { of genetic risk } \\
\text { LOD score 3.3, D11Mit272/D11Mit } 310 \text { with evidence for } \\
\text { interactions between Chr } 17 \text { and } 11\end{array}$ & [28] \\
\hline Bleomycin & $\begin{array}{l}\text { C57BL6 and } \\
\text { A/J congenic }\end{array}$ & Chr 9 & $\begin{array}{l}\text { LOD } 4.9 \text { at D9Mit } 236,246 \text { differentially expressed genes } \\
\text { mapped to the interval }\end{array}$ & [27] \\
\hline Bleomycin & $\begin{array}{l}\mathrm{C} 3 \mathrm{H}-\mathrm{H} 2 \\
\text { reduced } \\
\text { congenic }\end{array}$ & $\begin{array}{l}\text { MHC } \\
\text { susceptible }\end{array}$ & $\begin{array}{l}\text { Reduced levels of bleomycin hydrolase activity in the } \\
\text { fibrosis-prone strains }\end{array}$ & [29] \\
\hline Radiation & C57BL/6J & $\begin{array}{l}\text { Chr } 17 \\
\text { Chr } 1 \\
\text { Chr } 6\end{array}$ & $\begin{array}{l}\text { LOD } 4.2 \text { at D17Mit } 16 \text { within the bleomycin-linked region } \\
\text { LOD } 4.5 \text { at D1Mit } 206 \\
\text { LOD } 4.6 \text { at D6Mit } 254\end{array}$ & {$[31]$} \\
\hline
\end{tabular}

ties include oligoclonal expansion of $\mathrm{T}$ cells bearing restricted $\mathrm{T}$ cell receptor, increased expression of TNF-ligand and TNF-receptor superfamilies by T cells, B cell hyperactivity with spontaneous in situ production of immunoglobulin, and accumulation of antigen-presenting mononuclear monocytes/macrophages. There is also an increase in macrophage-derived cytokines (IL-1, IL-6, IL-8, IL-15, TNF- $\alpha$, IFN- $\gamma$ and GM-CSF), chemokines (RANTES, MIP-1 $\alpha$ and IL-16) and fibrogenic cytokines (TGF- $\beta$ and PDGF). Genes involved in each of these pathways are plausible biologic candidate genes.

The combination of the racial and ethnic differences in disease prevalence, and the characteristic immunologic features of the disease have focused attention on HLA region genes. In fact, utilizing mutation screening in candidate genes, only HLA alleles have been validated as susceptibility genes for sarcoidosis. Results from different populations have produced conflicting results, some HLA alleles demonstrating an increased risk with others offering protection from disease.

HLA class II alleles have been most frequently reported to be associated with an increased risk of developing sarcoidosis. There is a consistent association with HLADR3 haplotype with a more favorable prognosis in Czech, German, Italian, Japanese, Polish and Scandinavian populations [40-47]. The HLA-DRB1 and HLA-DQB1 alleles have been associated with milder forms of the disease (erythema nodosum, Löfgren's syndrome, stage $0 / 1$ chest Xray findings) in patients from Scandinavia, the UK and the Netherlands $[40,48]$. Of note, HLA-DQB1 is in linkage disequilibrium with HLA-DRB1, which is in close proximity to non-HLA-related genes such as TNF that may also influence outcomes [49]. The favorable outcome associated with increased TNF- $\alpha$ production based on the A2 promoter allele may be related to a common haplotype shared by HLA-DR3 [50]. Other HLA loci that confer disease susceptibility include HLA-A1, HLA-B8, HLA-B22, HLA-B13, HLA-DR15 and HLA-DR16, whereas protection from disease or milder forms of the disease have also been associated with HLA-DR17 and HLADRw52 [40, 46, 51-53].

A number of non-HLA genes have been investigated. The most heavily investigated is intron 16 of angiotensinconverting enzyme (ACE), which is known to affect serum ACE levels. However, there appears to be no relationship with disease susceptibility [54-56]. Other non-HLA candidate genes studied in sarcoidosis are summarized in table 2 . In interpreting these data, it is important to look closely at the choice of control populations to avoid spurious associations due to population stratification, as well as at the statistical methods such as verification that genetic markers are in Hardy-Weinberg equilibrium and that correction for multiple comparisons has been performed. It is also important to look for evidence of linkage disequilibrium in flanking putative disease susceptibility single nucleotide polymorphisms (SNPs), since unknown mutations in linkage disequilibrium with the putative disease susceptibility SNP may be responsible for the apparent association. In general, replication studies in multiple populations are necessary before a candidate gene SNP is unequivocally linked as a susceptibility gene. Currently, utilizing mutation screen- 
Table 2. Non-HLA candidate gene polymorphisms in sarcoidosis

\begin{tabular}{llll}
\hline Candidate gene & Polymorphism & Result & Reference \\
\hline ACE & intron 16 in/del & population specific & {$[40,56]$} \\
Vitamin D receptor & BsmI RFLP & increased risk & {$[57]$} \\
IL-1 cluster & IL- $\alpha$-889 & increase risk 2 & {$[58]$} \\
TGF- $\beta 3$ & 4785A & fibrotic sarcoid & {$[59]$} \\
HSP-70 hom & 2763, 2437 & Löfgren's syndrome & {$[60]$} \\
TLR4 & A299G, T399I & increased in chronic sarcoid & {$[61]$} \\
Nod2/Card15 & R702W, G908R, 1007FsinC & no effect & {$[62,63]$} \\
TNF- $\alpha$ & A2 promoter allele & favorable prognosis & {$[64]$} \\
CCR5 & HHC haplotype & persistent lung disease & {$[65]$} \\
HSP70-hom & C2437T & Löfgren's syndrome & {$[66]$} \\
TGF- $\beta$ & 4875A & fibrotic sarcoid & {$[67]$} \\
\hline Adjacent to or in linkage disequilibrium with HLA locus & & {$[68]$} \\
BTNL2 & 3 locus haplotype & increased risk & {$[69,70]$} \\
BTNL2 & 10 intron/exon 5 SNP & increased risk & \\
\hline
\end{tabular}

ing in candidate genes, only HLA alleles have been validated unequivocally as susceptibility genes for sarcoidosis.

\section{Linkage Analysis}

The first published genome-wide linkage study in sarcoidosis was from 63 German families consisting mostly of affected sibling pairs with 138 affected siblings and 95 first-degree relatives [71]. The greatest risk was in the MHC class II gene. Other chromosome regions showing potential associations include chromosomes $3 \mathrm{p} 21,1 \mathrm{p} 22$, 9q33, X,7q22 and 7q36. A second linkage study in sarcoidosis is from the Sarcoidosis Genetic Analysis Consortium (SAGA), reporting linkage analysis of sibling pairs from 229 African-American families utilizing 380 microsatellite markers. Interestingly, despite using a higher density of markers in the MHC class II region, the SAGA investigators did not find evidence for linkage in the MHC class II region [70]. They identified 15 markers with $p \leq 0.05$, with the most prominent peak at D5S2500 on chromosome $5 \mathrm{q} 11$ ( $\mathrm{p}=0.0005)$. The differing linkage results in the German and African-American populations are consistent with ethnicity-related locus heterogeneity.

Based on the initial linkage analysis of the 63 German families demonstrating linkage to chromosome 6p21, SNP-based fine mapping of the region was performed using extended families and trios to conduct transmission disequilibrium testing (TDT) and case-control association analysis [72]. The results demonstrated an associa- tion with an SNP located in the butyrophilin-like2 gene (BTNL2) located adjacent to HLA-DR1. The OR for developing sarcoidosis when heterozygous for the susceptibility allele is 1.6, and 2.75 in homozygotes. The BTNL2 gene was investigated further for disease susceptibility mutations using SNP-based fine mapping of the linkage region, utilizing family-based TDT and populationbased case-control association analyses, and a disease-associated variant, rs2076530, was associated with disease $\left(\mathrm{P}_{\mathrm{TDT}}=3 \times 10^{-6}, \mathrm{P}_{\text {case-control }}=1.1 \times 10^{-8}\right)$. This association appeared to be independent of variation in HLADRB1 gene located $180 \mathrm{~kb}$ centromeric to BTNL2. The rs2076530 variant represents a $G$ to $A$ transition resulting in cryptic splice site that results in the risk allele having a premature stop codon in the mRNA. The BTNL2 gene belongs to the immunoglobulin gene superfamily and is related to the costimulatory receptors B7.1 (CD80) and B7.2 (CD86), but its exact function is unknown. Replication of the susceptibility allele in BTNL2, rs2076530, was performed in an African-American family-based population, and in African-American and Caucasian casecontrol populations. In all 3 study populations there was a haplotype associated with sarcoidosis, but the association was much stronger in Caucasians $(p=0.0006)$ compared with the African-American family population $(\mathrm{p}=$ $0.03)$ or case-control population $(p=0.02)[69,70,73]$. These authors suggested that while in Caucasians the effects of BTNL2 are independent of HLA class II genes, there may be an antagonistic interaction between these loci in African-Americans. BTNL2 may play a role in 
T cell signaling, might interact with other HLA proteins and may explain some of the clinical differences in sarcoidosis among different ethnicities.

\section{Genetic Associations in Familial Interstitial Pneumonia}

Familial aggregation of otherwise IIPs has been reported in a variety of studies in twins, siblings raised apart and multigenerational families. When this occurs the disease is classified as familial interstitial pneumonia (FIP). There is no data on the relative proportion of interstitial pneumonias that are familial, but estimates are in the range of $5 \%$. While a single report suggests that FIP is inherited as an autosomal recessive trait [74], the majority of pedigrees demonstrate an autosomal dominant pattern of inheritance $[5,75,76]$, perhaps with reduced penetrance $[1,2,4-6,75,77,78]$.

Steele et al. [79] have reported on the largest collection of FIP, identifying 111 families from the US. In their study, 20 multigenerational pedigrees were consistent with autosomal dominant inheritance. Forty-five percent of the families demonstrated phenotypic heterogeneity, with some families having bronchiolitis obliterans, nonspecific interstitial pneumonia (NSIP) and usual interstitial pneumonia (UIP) within the same pedigree. Cigarette smoking was associated with affection status among siblings $(\mathrm{OR}=3.6,95 \%$ CI 1.3-9.8, $\mathrm{p}=0.01)$.

\section{Candidate Gene Studies}

Yang et al. [80] performed microarray analysis of 16 cases of sporadic IIP (14 UIP, 2 NSIP), 10 cases of FIP (6 UIP, 4 NSIP) and 9 matched normal lung controls. Whole human genome arrays modified with an additional 657 probes for genes/expressed sequence tags that would be potentially informative based on preliminary linkage data were used and expression profiling was performed using standard protocols. Differentially expressed genes were identified using significance analysis of microarrays with 100 permutations; 558 differentially expressed transcripts were identified, with 135 genes being up- or downregulated greater than 1.8 -fold. When hierarchical clustering was applied to the set of 135 genes, all but 2 samples clustered according to disease versus no disease, and familial disease segregated from sporadic disease. Sixtynine differentially expressed genes were identified that distinguish sporadic and familial interstitial pneumonia, and these are broadly grouped into functional classes with a wide variety of chemokines, extracellular matrix and growth-related genes that are differentially expressed. These data appear to indicate that familial and sporadic IIP are transcriptionally distinct, and also suggest similarities between the histologic subtypes of UIP and NSIP.

\section{Linkage Studies in Pulmonary Fibrosis}

The first published study performing genome-wide linkage analysis in FIP comes from Finland [81]. Using 6 pedigrees, associations on chromosomes 3 (marker D3S1278), 4 (marker D4S424) and 13 (D13S265) were obtained. On chromosome 4, a shared haplotype was identified among 8 of 24 multiplex families. A candidate gene located in the region of interest, ELMOD2, was further investigated by resequencing of exons and exon/intron boundaries. No mutations in ELMOD2 in these locations were identified. RT-PCR and in situ hybridization demonstrated decreased levels of ELMOD2 mRNA in 6 cases of sporadic idiopathic pulmonary fibrosis compared to controls. Telomerase mutations were identified in a genome-wide SNP linkage scan in 2 US Caucasian families displaying a logarithm of odds (LOD) score of 2.8 to chromosome $5 \mathrm{p} 15$. In one family, a deletion of thymidine at position 2241 of the cDNA created a frameshift mutation resulting in a predicted truncated protein, and in the second family an arginine to histidine mutation was identified at codon 865 [82]. Genome-wide linkage analysis of the 111 US families is in progress, and preliminary results indicate linkage (LOD score $>3.0$ ) on chromosome 11p15 not identified in the Finland study [Schwartz, pers. commun.].

\section{Genetic Determinants in Rare Inherited Disorders}

\section{Pulmonary Surfactant Abnormalities}

Pulmonary surfactant is a complex mixture of phospholipids and proteins (surfactant-associated proteins A, $\mathrm{B}, \mathrm{C}$ and $\mathrm{D}$ ) that likely has many functions and is known to reduce surface tension at the alveolar air interface preventing atelectasis. Deficiency of pulmonary surfactant is the principal cause of respiratory distress syndrome in premature infants [83], and familial cases of neonatal respiratory distress have been associated with SP-B deficiency [84].

Abnormalities in SP-C have been described in patients with DPLD. Nogee et al. [85] reported a full-term baby girl born to a woman who had had desquamative interstitial pneumonia at 1 year of age. The infant's maternal grandfather died of an unknown lung disease. The 
infant developed respiratory distress at the age of 6 weeks, and surgical lung biopsy demonstrated NSIP. Both the infant and mother had minimal SP-C by either immunohistochemical staining or immunoblotting of lung tissue. DNA sequence analysis of the SP-C gene demonstrated a heterozygous substitution of $A$ to $G$ at the first base of intron 4, resulting in a truncated mRNA. Subsequently, several additional families with both SP-C mutations and interstitial pneumonia have been described $[16,86]$. In the largest kindred, a heterozygous T to A substitution was identified in exon 5. In this pedigree, there was both adult-onset UIP histology and childhood cellular NSIP [16]. Immunohistochemical analysis of these patients demonstrated intracellular aggregates of SP-C and in vitro expression studies demonstrated abnormal intracellular processing of SP-C in alveolar type II cells.

SP-A variants have also been associated with an increased risk of idiopathic pulmonary fibrosis [87]. In a single study by Selman et al. [88] the SP-A1 $6 \mathrm{~A}^{4}$ haplotype was associated with a substitution of 3 amino acids at positions 19, 50 and 219. The amino acid 219 variant was associated with idiopathic pulmonary fibrosis in smokers and nonsmokers (OR $=3.67,95 \%$ CI $1.34-10.07$, $\mathrm{p}=0.01)$.

\section{Other Rare Disorders}

Pulmonary fibrosis is observed in genetic disorders with a pleiotropic clinical presentation, including Hermansky-Pudlak syndrome, neurofibromatosis, tuberous sclerosis, Niemann-Pick disease, Gaucher disease, familial hypocalciuric hypercalcemia, familial SP-C mutation, and most recently dyskeratosis congenita. Mutations associated with the dyskeratosis congenita syndrome have been identified in a small percentage of families with FIP [89]. Specifically, $8 \%$ of 73 families with more than 1 case of IIP were found to have heterozygous mutations in telomerase reverse transcriptase resulting in shortening of telomeres. These authors suggested that telomere shortening may cause apoptosis of the alveolar epitheli$\mathrm{um}$. At this time, the frequency of telomerase mutations in adult-onset sporadic or familial pulmonary fibrosis is uncertain.

\section{Emerging Concepts from Genetic Studies}

An interesting feature of these studies is the variable histopathologic features among family members sharing seemingly identical genetic abnormalities, suggesting modification of disease phenotype by the injury type or other unknown factors. Mutations in SP-C and telomerase reverse transcriptase also suggest that abnormalities of the alveolar epithelium, particularly alveolar type II epithelial cells, the major source of pulmonary surfactant and also the progenitor cell for alveolar type I epithelial cell, may be critical for the development of interstitial pneumonia. These studies support the shift in thinking about the mechanisms responsible for the development of fibrosing lung disease, away from an inflammatory hypothesis toward one of abnormal injury and repair of the alveolar epithelium.

\section{Summary}

The ILDs/DPLDs are a heterogeneous group of diseases with complex pathogenesis, diverse histopathology and variable natural history. It is becoming increasingly clear that these entities occur in genetically susceptible individuals combined with specific triggers such as environmental and drug exposure. High-risk alleles for the development and prognosis of sarcoidosis have been recently identified and linkage and candidate gene studies are identifying susceptibility genes for the development of pulmonary fibrosis. Future challenges include determining how multiple susceptibility alleles interact with each other and environmental factors, resulting in disease risk and multiple phenotypes, and determining the mechanism of action and cellular pathways involving susceptibility alleles. These approaches will ultimately aid future diagnostic and treatment algorithms in ILD.

Insight into the genetics of ILDs/DPLD raises important practical issues for the clinician [90]. First, while susceptibility alleles are being identified in sarcoidosis and IIPs, genetic screening for these high-risk alleles is currently not feasible. Furthermore, high-risk alleles are likely one of several risk factors leading to the development of complex diseases such as sarcoidosis and IIP, and further insight into identifying all the relevant disease risk factors is needed. Certainly, obtaining a detailed family history is important, and can assist in the diagnostic evaluation of patients with DPLD/ILDs. One question that arises is what to do with unaffected familial members in terms of screening for asymptomatic disease. Until the natural history of early, asymptomatic disease is determined in these individuals, there are no definite guidelines. In FIP, the diagnosis of UIP in 1 family member does not imply all family members will have UIP, and 
each family member should be considered for surgical lung biopsy depending on the clinical presentation and high-resolution chest CT features. Unaffected familial members with FIP should be urged to stop cigarette smok- ing. There is no data on the treatment of familial forms of IIP or sarcoidosis. At this time, it seems prudent to treat patients with familial forms of IIP or sarcoidosis similar to the treatment of sporadic forms of the disease.

\section{References}

1 JavaheriS, et al: Idiopathic pulmonary fibrosis in monozygotic twins: the importance of genetic predisposition. Chest 1980;78:591594.

-2 Solliday NH, et al: Familial chronic interstitial pneumonia. Am Rev Respir Dis 1973; 108:193-204

3 Bonanni PP, Frymoyer JW, Jacox RF: A family study of idiopathic pulmonary fibrosis: a possible dysproteinemic and genetically determined disease. Am J Med 1965;39:411421.

4 Hughes EW: Familial interstitial pulmonary fibrosis. Thorax 1964;19:515-525.

5 Swaye P, et al: Familial Hamman-Rich syndrome. Chest 1969;55:7-12.

6 Bitterman PB, et al: Familial idiopathic pulmonary fibrosis: evidence of lung inflammation in unaffected members. N Engl J Med 1986;314:1343-1347.

7 Lee HL, et al: Familial idiopathic pulmonary fibrosis: clinical features and outcome. Chest 2005;127:2034-2041.

8 Hodgson U, Laitinen T, Tukiainen P: Nationwide prevalence of sporadic and familial idiopathic pulmonary fibrosis: evidence of founder effect among multiplex families in Finland. Thorax 2002;57:338-342.

$\checkmark 9$ Depinho RA, Kaplan KL: The HermanskyPudlak syndrome: report of three cases and review of pathophysiology and management considerations. Medicine 1985;64:192-202.

10 Riccardi V: Von Recklinghausen neurofibromatosis. N Engl J Med 1981;305:1617-1627.

11 Harris J, Waltuck B, Swenson E: The pathophysiology of the lungs in tuberous sclerosis: a case report and literature review. Am Rev Respir Dis 1969;100:379-387.

12 Makle SK, Pardee N, Martin CJ: Involvement of the lung in tuberous sclerosis. Chest 1970; 58:538-540.

$\checkmark 13$ Terry R, Sperry W, Brodoff B: Adult lipoidosis resembling Neimann-Pick disease. Am J Pathol 1954;30:263-286.

14 Schneider E, et al: Severe pulmonary involvement in adult Gaucher's disease: report of three cases and review of the literature. Am J Med 1977;63:475-480.

15 Auwerx J, et al: Defective host defence mechanisms in a family with hypocalciuric hypercalcaemia and coexisting interstitial lung disease. Clin Exp Immunol 1985;62:57-64.

Genetic Predisposition to Respiratory Diseases
16 Thomas AQ, et al: Heterozygosity for a surfactant protein $\mathrm{C}$ gene mutation associated with usual interstitial pneumonitis and cellular nonspecific interstitial pneumonitis in one kindred. Am J Respir Crit Care Med 2002;165:1322-1328.

17 Polakoff PL, Horn BR, Scherer OR: Prevalence of radiographic abnormalities among Northern California shipyard workers. Ann NY Acad Sci 1979;33:333-339.

18 Selikoff IJ, Lilis R, Nicholson WJ: Asbestos disease in United States shipyards. Ann NY Acad Sci 1979;330:293-311.

19 Ortiz LA, et al: Expression of TNF and the necessity of TNF receptors in bleomycin-induced lung injury in mice. Exp Lung Res 1998;24:721-743.

20 Rossi G, et al: Susceptibility to experimental interstitial lung disease is modified by immune- and non-immune related genes. Am Rev Respir Dis 1987;135:448-455.

21 Corsini E, et al: A protective role for $\mathrm{T}$ lymphocytes in asbestos-induced pulmonary inflammation and collagen deposition. Am J Respir Cell Mol Biol 1994;11:531-539.

22 Warshamana GS, et al: Susceptibility to asbestos-induced and transforming growth factor- $\beta 1$-induced fibroproliferative lung disease in two strains of mice. Am J Respir Cell Mol Biol 2002;27:705-713.

23 Franko AJ, et al: Evidence for two patterns of inheritance of sensitivity to induction of lung fibrosis in mice by radiation, one of which involves two genes. Radiat Res 1996; 146:68-74.

24 Haston CK, Travis EL: Murine susceptibility to radiation-induced pulmonary fibrosis is influenced by a genetic factor implicated in susceptibility to bleomycin-induced pulmonary fibrosis. Cancer Res 1997;57:52865291.

25 Sharplin J, Franko A: Quantitative histological study of strain-dependent differences in the effects of irradiation on mouse lung during the early phase. Radiat Res 1989;119:114.

26 Haston CK, et al: Inheritance of susceptibility to bleomycin-induced pulmonary fibrosis in the mouse. Cancer Res 1996;56:2596-2601.

27 Haston CK, et al: Murine candidate bleomycin induced pulmonary fibrosis susceptibility genes identified by gene expression and sequence analysis of linkage regions. J Med Genet 2005;42:464-473.
28 Haston CK, et al: Bleomycin hydrolase and a genetic locus within the MHC affect risk for pulmonary fibrosis in mice. Hum Mol Genet 2002;11:1855-1863.

29 Lemay AM, Haston CK: Bleomycin-induced pulmonary fibrosis susceptibility genes in $\mathrm{AcB} / \mathrm{BcA}$ recombinant congenic mice. Physiol Genomics 2005;23:54-61.

30 Katsuma S, et al: Molecular monitoring of bleomycin-induced pulmonary fibrosis by cDNA microarray-based gene expression profiling. Biochem Biophys Res Commun 2001;288:747-751

31 Haston CK, et al: Universal and radiationspecific loci influence murine susceptibility to radiation-induced pulmonary fibrosis. Cancer Res 2002;62:3782-3788.

32 Rybicki BA, et al: Familial aggregation of sarcoidosis: a case-control etiologic study of sarcoidosis (ACCESS). Am J Respir Crit Care Med 2001;164:2085-2091.

33 Rybicki BA, et al: Familial risk ratio of sarcoidosis in African-American sibs and parents. Am J Epidemiol 2001;153:188-193.

34 Buck AA, Mc KV: Epidemiologic investigations of sarcoidosis. III. Serum proteins; syphilis; association with tuberculosis: familial aggregation. Am J Hyg 1961;74:174188.

35 Harrington D, et al: Familial analysis of 91 families. Sarcoidosis 1994;11:240-243.

36 Headings VE, et al: Familial sarcoidosis with multiple occurrences in eleven families: a possible mechanism of inheritance. Ann NY Acad Sci 1976;278:377-385.

37 Moura M, et al: Sarcoidosis and heredity: 3 familial cases. Rev Pneumol Clin 1990;46: 28-30.

38 Wiman LG: Familial occurrence of sarcoidosis. Scand J Respir Dis 1972;80(suppl):115119.

39 Statement on sarcoidosis. Joint Statement of the American Thoracic Society (ATS), the European Respiratory Society (ERS) and the World Association of Sarcoidosis and Other Granulomatous Disorders (WASOG) adopted by the ATS Board of Directors and by the ERS Executive Committee, February 1999. Am J Respir Crit Care Med 1999;160:736755 .

40 Berlin M, et al: HLA-DR predicts the prognosis in Scandinavian patients with pulmonary sarcoidosis. Am J Respir Crit Care Med 1997;156:1601-1605. 
41 Bogunia-Kubik K, et al: HLA-DRB1*03, $\mathrm{DRB1}^{*} 11$ or DRB1*12 and their respective DRB3 specificities in clinical variants of sarcoidosis. Tissue Antigens 2001;57:87-90.

42 Foley PJ, et al: Human leukocyte antigenDRB1 position 11 residues are a common protective marker for sarcoidosis. Am J Respir Cell Mol Biol 2001;25:272-277.

43 Gardner J, et al: HLA associations in sarcoidosis: a study of two ethnic groups. Thorax 1984;39:19-22.

44 Ina Y, et al: HLA and sarcoidosis in the Japanese. Chest 1989;95:1257-1261.

-45 Ishihara M, et al: Molecular genetic studies of HLA class II alleles in sarcoidosis. Tissue Antigens 1994;43:238-241.

46 Martinetti M, et al: 'The sarcoidosis map': a joint survey of clinical and immunogenetic findings in two European countries. Am J Respir Crit Care Med 1995;152:557-564.

47 Swider C, et al: TNF- $\alpha$ and HLA-DR genotyping as potential prognostic markers in pulmonary sarcoidosis. Eur Cytokine Netw 1999; 10:143-146.

-48 Sato H, et al: HLA-DQB1*0201: a marker for good prognosis in British and Dutch patients with sarcoidosis. Am J Respir Cell Mol Biol 2002;27:406-412.

-49 Mrazek F, et al: Association of tumour necrosis factor- $\alpha$, lymphotoxin- $\alpha$ and HLADRB1 gene polymorphisms with Lofgren's syndrome in Czech patients with sarcoidosis. Tissue Antigens 2005;65:163-171.

-50 Seitzer U, Gerdes J, Muller-Quernheim J: Genotyping in the MHC locus: potential for defining predictive markers in sarcoidosis. Respir Res 2002;3:6.

-51 Grunewald J, Eklund A, Olerup O: Human leukocyte antigen class I alleles and the disease course in sarcoidosis patients. Am J Respir Crit Care Med 2004;169:696-702.

52 Rossman MD, et al: HLA-DRB1*1101: a significant risk factor for sarcoidosis in blacks and whites. Am J Hum Genet 2003;73:720735.

53 Maliarik M, et al: Analysis of HLA-DPB1 polymorphisms in African-Americans with sarcoidosis. Am J Respir Crit Care Med 1998; 158:111-114.

54 Maliarik MJ, et al: Angiotensin-converting enzyme gene polymorphism and risk of sarcoidosis. Am J Respir Crit Care Med 1998; 158:1566-1570.

55 Alia P, et al: Association between ACE gene I/D polymorphism and clinical presentation and prognosis of sarcoidosis. Scand J Clin Lab Invest 2005,65:691-697.

56 McGrath DS, et al: Ace gene I/D polymorphism and sarcoidosis pulmonary disease severity. Am J Respir Crit Care Med 2001; 164:197-201.
Niimi T, et al: Vitamin D receptor gene polymorphism and calcium metabolism in sarcoidosis patients. Sarcoidosis Vasc Diffuse Lung Dis 2000;17:266-269.

58 Niimi T, et al: Lack of association with interleukin 1 receptor antagonist and interleukin-1 $\beta$ gene polymorphisms in sarcoidosis patients. Respir Med 2000;94:1038-1042.

59 Kruit A, et al: Transforming growth factor- $\beta$ gene polymorphisms in sarcoidosis patients with and without fibrosis. Chest 2006;129: 1584-1591.

60 Bogunia-Kubik K, et al: HSP70-hom gene single nucleotide $(+2763 \mathrm{G} / \mathrm{A}$ and $+2437 \mathrm{C} / \mathrm{T})$ polymorphisms in sarcoidosis. Int J Immunogenet 2006;33:135-140.

61 Pabst S, et al: Toll-like receptor (TLR) 4 polymorphisms are associated with a chronic course of sarcoidosis. Clin Exp Immunol 2006; 143:420-426.

62 Kanazawa N, et al: Early-onset sarcoidosis and CARD15 mutations with constitutive nuclear factor- $\kappa \mathrm{B}$ activation: common genetic etiology with Blau syndrome. Blood 2005;105:1195-1197.

63 Martin TM, et al: Uveitis in patients with sarcoidosis is not associated with mutations in NOD2 (CARD15). Am J Ophthalmol 2003;136:933-935.

64 Sabounchi-Schutt F, et al: Changes in bronchoalveolar lavage fluid proteins in sarcoidosis: a proteomics approach. Eur Respir J 2003;21:414-420.

65 Spagnolo P, et al: C-C chemokine receptor 5 gene variants in relation to lung disease in sarcoidosis. Am J Respir Crit Care Med 2005; 172:721-728.

66 Zorzetto M, et al: Complement receptor 1 gene polymorphisms in sarcoidosis. Am J Respir Cell Mol Biol 2002;27:17-23.

67 Takada T, et al: Polymorphism in RANTES chemokine promoter affects extent of sarcoidosis in a Japanese population. Tissue Antigens 2001;58:293-298.

68 Akahoshi M, et al: Association between IFNA genotype and the risk of sarcoidosis. Hum Genet 2004;114:503-509.

69 Rybicki BA, et al: The BTNL2 gene and sarcoidosis susceptibility in African Americans and Whites. Am J Hum Genet 2005;77:491499.

70 Iannuzzi MC, et al: Genome-wide search for sarcoidosis susceptibility genes in African Americans. Genes Immun 2005;6:509-518.

71 Schurmann M, et al: Results from a genomewide search for predisposing genes in sarcoidosis. Am J Respir Crit Care Med 2001; 164:840-846.

72 Valentonyte R, et al: Sarcoidosis is associated with a truncating splice site mutation in BTNL2. Nat Genet 2005;37:357-364.

73 Gray-McGuire C, et al: Genetic characterization and fine mapping of susceptibility loci for sarcoidosis in African Americans on chromosome 5. Hum Genet 2006; 120:420430.
74 Tsukahara M, Kajii T: Interstitial pulmonary fibrosis in two sisters: possible autosomal recessive inheritance. Jinrui Idengaku Zasshi 1983;28:263-267.

75 Adelman AG, Chertkow G, Hayton RC: Familial fibrocystic pulmonary dysplasia: a detailed family study. Can Med Assoc J 1966; 95:603-610.

76 McKusick VA, Fisher AM: Congenial cystic disease of the lung with progressive pulmonary fibrosis and carcinomatosis. Ann Intern Med 1958;48:774-790.

77 Musk AW, et al: Genetic studies in familial fibrosing alveolitis. Possible linkage with immunoglobulin allotypes (Gm). Chest 1986;89:206-210.

78 Marshall R, et al: Adult familial cryptogenic fibrosing alveolitis in the United Kingdom. Thorax 2000;55:143-146.

79 Steele MP, et al: Clinical and pathologic features of familial interstitial pneumonia. Am J Respir Crit Care Med 2005;172:1146-1152.

80 Yang IV, et al: Gene expression profiling of familial and sporadic interstitial pneumonia. Am J Respir Crit Care Med 2007;175: 45-54.

81 Hodgson U, et al: ELMOD2 is a candidate gene for familial idiopathic pulmonary fibrosis. Am J Hum Genet 2006;79:149-154.

82 Tsakiri KD, et al: Adult-onset pulmonary fibrosis caused by mutations in telomerase. Proc Natl Acad Sci USA 2007;104:75527557.

83 Whitsett JA, Weaver TE: Hydrophobic surfactant proteins in lung function and disease. N Engl J Med 2002;347:2141-2148.

84 Nogee LM, et al: Allelic heterogeneity in hereditary surfactant protein B (SP-B) deficiency. Am J Respir Crit Care Med 2000;161: 973-981.

85 Nogee LM, et al: A mutation in the surfactant protein $\mathrm{C}$ gene associated with familial interstitial lung disease. N Engl J Med 2001; 344:573-579.

86 Chibbar R, et al: Nonspecific interstitial pneumonia and usual interstitial pneumonia with mutation in surfactant protein $\mathrm{C}$ in $\mathrm{fa}$ milial pulmonary fibrosis. Mod Pathol 2004; 17:973-980.

87 Lawson WE, et al: Genetic mutations in surfactant protein $\mathrm{C}$ are a rare cause of sporadic cases of IPF. Thorax 2004;59:977-980.

88 Selman M, et al: Surfactant protein A and B genetic variants predispose to idiopathic pulmonary fibrosis. Hum Genet 2003;113: 542-550. Epub 2003.

89 Armaniaos MY, et al: Telomerase mutations in families with idiopathic pulmonary fibrosis. N Engl J Med 2007;356:1317-1326.

90 Cottin V: Clinical genetics for the pulmonologist: introduction. Respiration 2007;74: 3-7. 